\title{
Short communication: Identification of iron-binding peptides from whey protein hydrolysates using iron (III)-immobilized metal ion affinity chromatography and reversed phase-HPLC-tandem mass spectrometry
}

\author{
Elvia Cruz-Huerta, ${ }^{*}$ Daniel Martínez Maqueda, ${ }^{*}$ Isidra Recio, Lucia de la Hoz, $†$ Vera S. Nunes da Silva, $\dagger$ \\ Maria Teresa Bertoldo Pacheco,† and Lourdes Amigo*1 \\ *Instituto de Investigación en Ciencias de la Alimentación, Consejo Superior de Investigaciones Científicas-Universidad Autónoma de Madrid, \\ Nicolás Cabrera, 9, 28049 Madrid, Spain \\ †Instituto de Tecnología de Alimentos, Centro de Ciência e Qualidade de Alimentos, Av. Brasil, 2880, CP 139, CEP 13070-178, Campinas, \\ SP, Brazil
}

\begin{abstract}
Peptides with iron-binding capacity obtained by hydrolysis of whey protein with Alcalase (Novozymes, Araucaria, PR, Brazil), pancreatin, and Flavourzyme (Novozymes) were identified. Hydrolysates were subjected to iron (III)-immobilized metal ion affinity chromatography, and the bound peptides were sequenced by mass spectrometry. Regardless of the enzyme used, the domains $\mathrm{f}(42-59)$ and $\mathrm{f}(125-137)$ from $\beta$-lactoglobulin enclosed most of identified peptides. This trend was less pronounced in the case of peptides derived from $\alpha$-lactalbumin, with sequences deriving from diverse regions. Iron-bound peptides exhibited common structural characteristics, such as an abundance of Asp, Glu, and Pro, as revealed by mass spectrometry and AA analysis. In conclusion, this characterization of ironbinding peptides helps clarify the relationship between peptide structure and iron-chelating activity and supports the promising role of whey protein hydrolysates as functional ingredients in iron supplementation treatments.
\end{abstract}

Key words: whey protein, enzymatic hydrolysis, ironbinding peptide, reversed phase HPLC-tandem mass spectrometry

\section{Short Communication}

Iron constitutes one of the most essential trace elements in human nutrition. According to the World Health Organization (WHO/FAO, 2004), iron deficiency represents one of the most important nutritional disorders worldwide, and is especially common under states of increased iron requirement, insufficient intake,

Received May 20, 2015.

Accepted September 4, 2015.

${ }^{1}$ Corresponding author: lourdes.amigo@csic.es or decreased bioavailability. There has been great interest over the years in the study of metal-chelating peptides. Recent reports have demonstrated improved iron-binding capacity or bioavailability for peptides from diverse sources (Guo et al., 2014).

Whey, which contains around $20 \%$ of milk proteins, represents a major by-product of cheese manufacturing process (Smithers, 2008). Although casein contains more sites and greater affinity to bind iron than whey proteins, due to the presence of phosphoserine residues, the binding of iron by whey proteins has also been described (Sugiarto et al., 2009). In a study for the optimization of the iron-binding capacity for enzymatic hydrolysis of $\beta$-LG, Zhou et al. (2012) reported that whole $\beta$-LG exhibited the lowest capacity compared with any of the hydrolysates tested. Hydrolysis of whey proteins with different enzymes has been reported to release peptides with iron-chelating capacity; for example, hydrolysates prepared with Alcalase (Novozymes, Araucaria, PR, Brazil; Kim et al., 2007), Corolase PP (AB Enzymes GmbH, Darmstadt, Germany; O'Loughlin et al., 2014) or papain and Neutrase (Novozymes; Ou et al., 2010). However, only a few iron-binding peptides have been characterized and, to our knowledge, no whey-derived peptides have been yet identified. This lack of knowledge about the relationship between peptide structure and iron-chelating activity prevents researchers from anticipating binding activity based on a peptide's sequence.

The proteolytic activity of Alcalase, pancreatin, and Flavourzyme (Novozymes) on whey proteins is notable compared with that of other enzymes (Kim et al., 2007). Recently, we found that the $<5 \mathrm{kDa}$ fraction from whey protein hydrolysates obtained individually with these 3 enzymes showed a marked iron-chelating capacity detected by an enhancement of iron dialyzability (de la Hoz et al., 2014a).

The aim of the current study was to identify peptides with affinity for iron in these hydrolysates, and 
the comparative analysis of total amino acid profile. The peptide structure required to exhibit iron-binding properties is discussed.

Enzymatic hydrolysates were prepared according to de la Hoz et al., (2014a). Briefly, a whey protein isolate (Provon Protein, Glanbia Nutritionals, Kilkenny, Ireland) at $10 \%$ (wt/vol) was hydrolyzed by Alcalase (Novozymes, Araucaria, PR, Brazil), pancreatin (Sigma-Aldrich, Saint-Quentin-Fallavier, France), and Flavourzyme (Novozymes). As result of an experimental rotatable central composite design with $\mathrm{pH}$ and enzyme-to-substrate ratio $(\mathbf{E} / \mathbf{S})$ as independent variables and the degree of hydrolysis as the measured response, optimal conditions were defined as $\mathrm{pH} 8, \mathrm{E} / \mathrm{S}$ ratio of $1.0 \%$ (wt/wt), and $60^{\circ} \mathrm{C}$ (Alcalase); $\mathrm{pH} 8, \mathrm{E} / \mathrm{S}$ ratio of $4.0 \%$ (wt/wt), and $40^{\circ} \mathrm{C}$ (pancreatin); and $\mathrm{pH} 6.7, \mathrm{E} / \mathrm{S}$ ratio of $2.6 \%$ (wt/wt), and $55^{\circ} \mathrm{C}$ (Flavourzyme). Hydrolysis was carried out using a Mettler-Toledo DL21 $\mathrm{pH}$-stat (Mettler-Toledo, Columbus, $\mathrm{OH}$ ) to reach a degree of hydrolysis up to $21.40 \%$ (Alcalase), $23.73 \%$ (pancreatin), and $16.28 \%$ (Flavourzyme). Hydrolysate fractionation was performed by an ultrafiltration system with Prep/ScaleTM-TFF cartridges with nominal cut-off of $5 \mathrm{kDa}$ (Pellicon Millipore, Bedford, MA). Fractions $<5 \mathrm{kDa}$ were lyophilized and stored at $-20^{\circ} \mathrm{C}$ until use. Iron-binding peptides were isolated from $<5$ $\mathrm{kDa}$ fractions as described in de la Hoz et al. (2014b). Briefly, immobilized metal ion affinity chromatography (IMAC) resin Sepharose High Performance (GE Healthcare Bio-Science, Uppsala, Sweden; $10 \mathrm{~mL}$ ) was charged with $\mathrm{Fe}$ (III) ( $5 \mathrm{~mL}$ of $200 \mathrm{mmol} / \mathrm{L} \mathrm{FeCl}_{3}$ ). The column was washed with Milli-Q water (Millipore, Billerica, MA) and then with sodium acetate buffer (50 mM, pH 3.6) to remove unbound and nonspecific bound iron and equilibrate the column. Three-milliliter aliquots of $<5 \mathrm{kDa}$ fractions $(20 \mathrm{mg}$ of protein $/ \mathrm{mL}$ ) were loaded onto the column at room temperature and bound peptides were eluted at a flow rate of $2 \mathrm{~mL} / \mathrm{min}$ using $\mathrm{NH}_{4} \mathrm{H}_{2} \mathrm{PO}_{4}$ buffer $(100 \mathrm{mmol} / \mathrm{L}, \mathrm{pH}$ 4.5). The eluate was monitored at $280 \mathrm{~nm}$, collected, lyophilized, and stored at $-20^{\circ} \mathrm{C}$ until use. Peptides were identified by using reversed-phase HPLC-tandem mass spectrometry according to Martínez-Maqueda et al. (2013). Samples were injected at a protein concentration of $2 \mathrm{mg} / \mathrm{mL}$ for $<5 \mathrm{kDa}$ fractions and $1 \mathrm{mg} / \mathrm{mL}$ for IMAC-Fe (III) eluted fractions, and analyzed over 2 mass-to-charge $(\mathrm{m} / z)$ ranges: $100-1,500$ and $100-3,000$, selecting molecular ion targets of 750 and $1,500(\mathrm{~m} / z)$, respectively.

For determination of the AA profile, a sample cleanup was carried out by the use of solid-phase extraction in anion mixed mode. Samples suspended in $2 \% \mathrm{NH}_{4} \mathrm{OH}$ (vol/vol) were applied to Bond Elut PAX cartridges (Waters, Santa Clara, CA) and sequentially eluted with methanol and 5\% formic acid (vol/vol methanol).
Samples with norleucine as internal standard were subjected to acid hydrolysis with $6 \mathrm{M} \mathrm{HCl}$ at $110^{\circ} \mathrm{C}$ for 21 $\mathrm{h}$ (controlled atmosphere). A Biochrom 30 Amino Acid Analyzer (Amersham-Pharmacia Biotech, Piscataway, NJ) was used to quantify AA after separation by cation exchange chromatography and postcolumn ninhydrin derivatization.

Figure 1 shows the identified peptides from $\beta$-LG, the major protein of bovine whey in the IMAC-Fe (III)bound fractions. Regardless of the enzyme used, ironbinding peptides could be grouped in 2 regions: $\beta$-LG $\mathrm{f}(42-59)$ and $\beta$-LG f(122-137), which enclosed most of the peptides identified. This situation was especially significant in the case of pancreatin, where no IMACFe (III)-bound peptides from different regions were found. Interestingly, these 2 domains are rich in negatively charged AA, such as Glu and Asp. In the region $\mathrm{f}(42-59), 5$ of the 18 AA are Glu or Asp, whereas in the region $\mathrm{f}(122-137)$, up to 6 of the 16 residues correspond to these negatively charged residues. As an example, Figure 2 shows the MS/MS fragmentation pattern of the identified peptide TPEVDDE that corresponds to $\beta$-LG $\mathrm{f}(125-131)$, one of the most representative domains. In this peptide, 4 of the $7 \mathrm{AA}$ are negatively charged and it contains a Pro residue.

Figure 3 shows the $\alpha$-LA-derived peptides identified in the IMAC-Fe (III)-bound fraction after hydrolysis with Alcalase, pancreatin, and Flavourzyme. Both Flavourzyme and pancreatin rendered highly negatively charged peptides from the region $\alpha$-LA f(81-88), where 5 of 8 residues correspond to Asp. Hydrolysis with Alcalase and pancreatin yielded a higher number of $\alpha$-LA IMAC-bound peptides compared with hydrolysis with Flavourzyme.

A detailed characterization of $<5 \mathrm{kDa}$ and IMAC-Fe (III)-derived fractions is presented in Supplementary Table S1 (http://dx.doi.org/10.3168/jds.2015-9839). A high proportion of peptides identified in the fraction $<5 \mathrm{kDa}$ after hydrolysis with Flavourzyme were bound to the IMAC-Fe (III) column. In contrast, the percentage of bound peptides considerably decreased in the hydrolysates with the other 2 enzymes, especially with Alcalase. The structure of $\beta-\mathrm{LG}$ is known to be very stable - a compact globular conformation stabilized by 2 intramolecular disulfide bonds, which restricts the action of certain enzymes under common physicochemical conditions (Otte et al., 1997). This feature would explain the wide regions of the protein with scarce or null coverage. In the current study, analysis of peptides was performed without previous reduction of disulfide bonds. Based on previous results from our group where several $\beta$-LG heterodimers bound through disulfide bridges were found (Martínez-Maqueda et al., 2013) and given the geometry of these peptides, it does not 
seem likely that these forms were present in the $<5 \mathrm{kDa}$ permeate used as substrate before the IMAC-Fe (III). On the other hand, the broad endoproteinase activity and substrate specificity of Alcalase and the endoproteinase and exopeptidase activities of Flavourzyme could explain the presence of peptides from different $\beta$-LG regions (O'Keeffe and FitzGerald, 2014). Among the enzymatic treatments, hydrolysis with Flavourzyme yielded the greatest variety of iron-binding peptides.

We analyzed the AA profile to provide information about the most abundant AA in the IMAC-Fe (III)bound fractions. Figure 4 shows, for each enzyme treatment, the relative content of different $\mathrm{AA}$ in the parental $(<5 \mathrm{kDa})$ and IMAC-Fe (III)-derived fractions, which shows the enrichment of certain AA by IMAC-Fe (III) chromatography. Regardless of the enzyme used to prepare the hydrolysate, Asp and Glu were significantly enriched in the chromatographic bound fractions, especially in those obtained with pancreatin and Fla- vourzyme. A known limitation of AA determination is the deamination of Asn and Gln during sample preparation, with the deaminated AA being detected as Asp and Glu, respectively. However, it is logical that the iron-bound fractions are enriched in acidic AA, based in the results obtained by tandem mass spectrometry. These AA (Asp and Glu) achieved the highest increases in IMAC-Fe (III)-bound fractions compared with the $<5 \mathrm{kDa}$ hydrolysate with percentage differences up to 8.9 and 11.2 units for pancreatin, respectively (Figure 4). Moreover, Pro showed an increase of 4.5 percentage units in the Fe-binding fraction relative to the hydrolysate obtained with Flavourzyme. In fact, Pro, at $10.9 \%$, constituted the third most abundant $\mathrm{AA}$ in the IMAC-Fe (III)-bound fraction obtained from the Flavourzyme hydrolysate, which is consistent with the results obtained by mass spectrometry. In contrast, other AA decreased in the iron-bound fraction. The content of Leu was remarkably reduced in IMAC-Fe

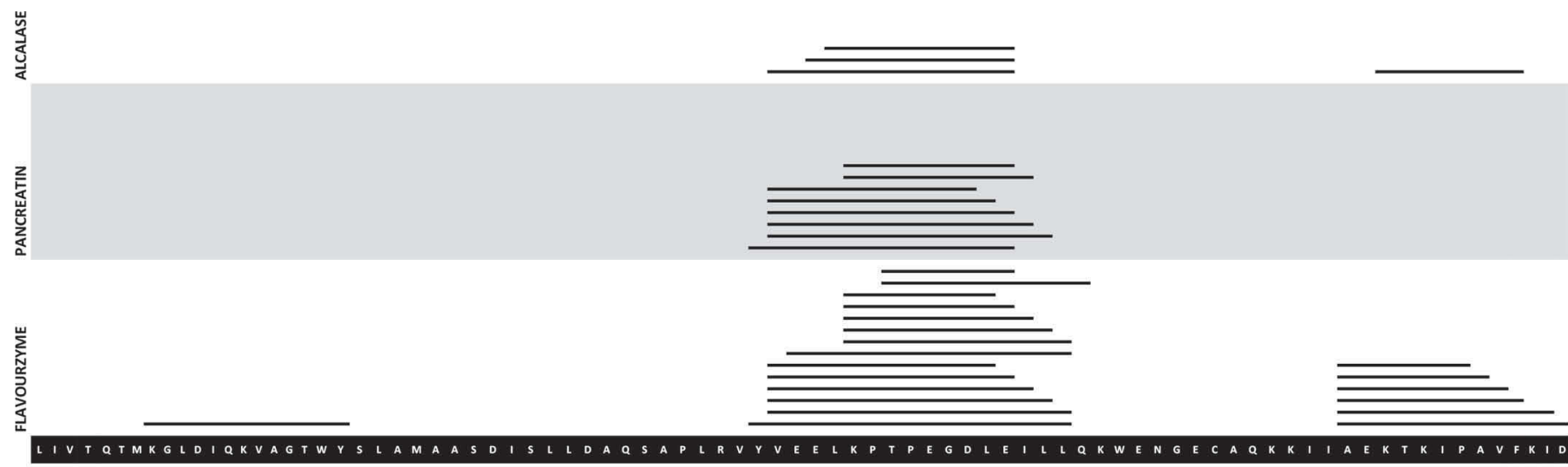

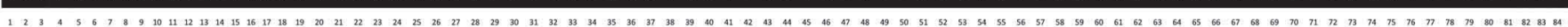
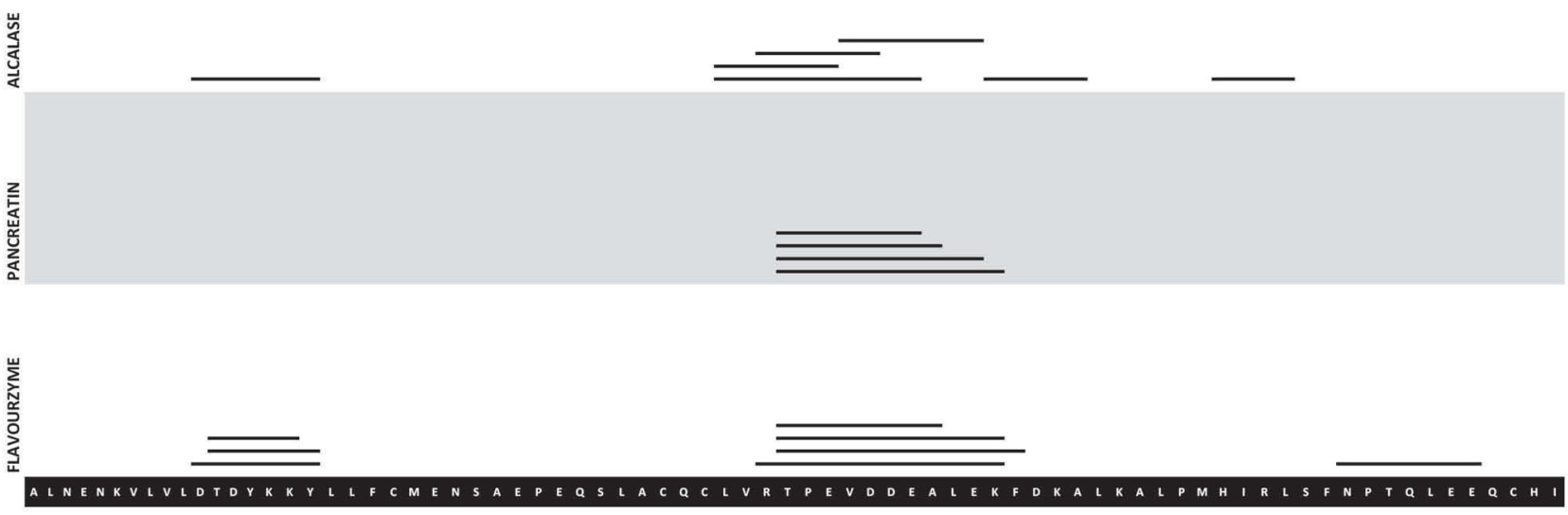

Figure 1. Schematic representation of peptides identified from bovine $\beta$-LG in fractions derived from iron (III)-immobilized metal ion affinity chromatography for different enzymatic treatments: Alcalase (Novozymes, Araucaria, PR, Brazil), pancreatin, and Flavourzyme (Novozymes). Identification was performed by reversed-phase HPLC-tandem mass spectrometry. 


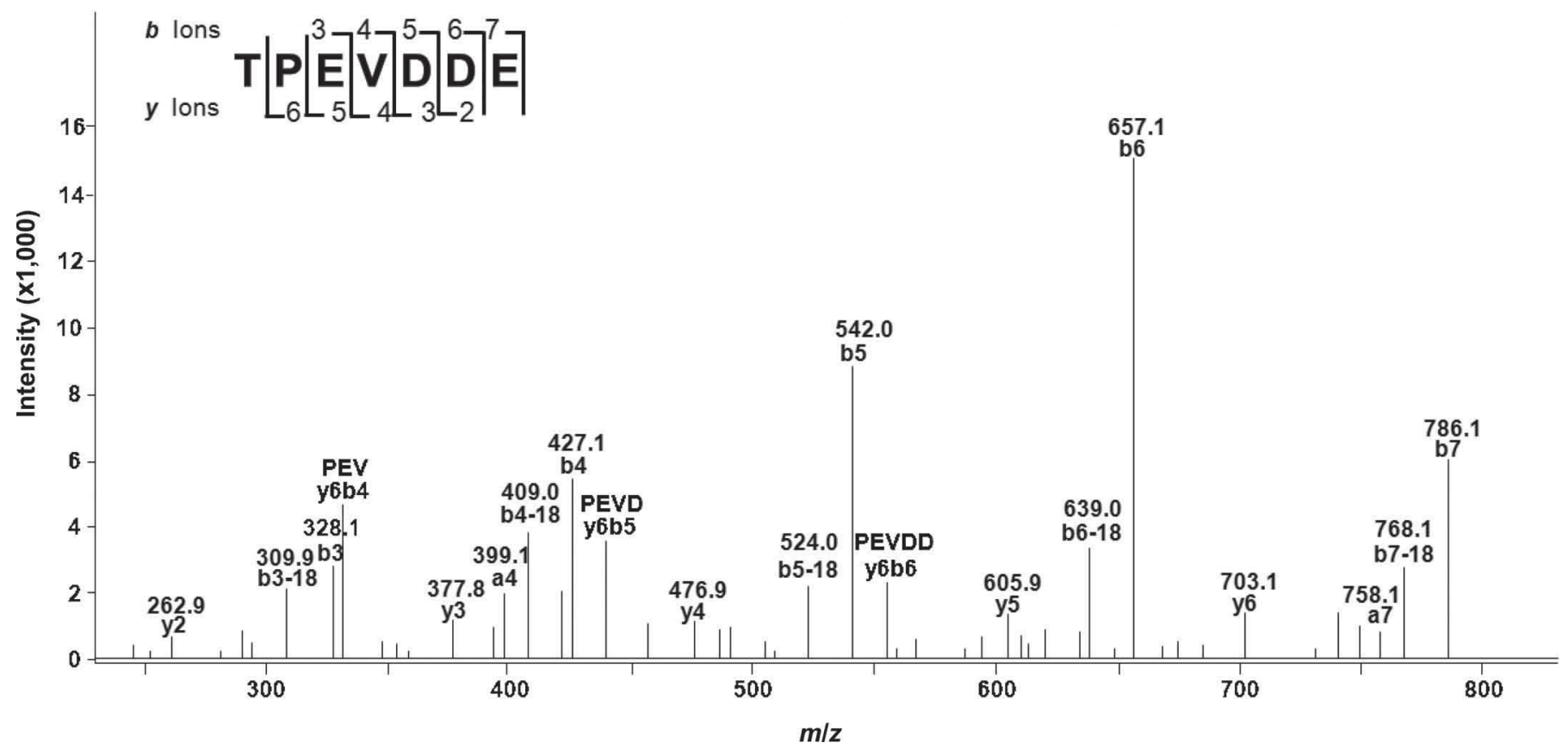

Figure 2. Tandem mass spectrum of ion $m / z$ 804.3. Following sequence interpretation and database searching, the peptide was identified as $\beta$-LG $\mathrm{f}(125-131)$. The sequence of this peptide is displayed with the (major) fragment ions observed in the spectrum.

(III) fractions, with decreases of 4.3, 7.6, and 7.5\% relative to that of Alcalase, pancreatin, and Flavourzyme $<5 \mathrm{kDa}$ hydrolysates, respectively.

The key role of Asp, Glu, and Pro in the chelation of iron has been reported previously. For instance, the enrichment of peptides in these AA is associated with enhanced iron uptake by $\mathrm{Caco}-2$ cells (Ou et al., 2010) and the positive effect of meat on nonheme iron bioavailability (meat factor; Storcksdieck genannt Bonsmann and Hurrell, 2007). It is reported that Asp and Glu form very stable iron chelates with a probable tridentate structure (Perrin, 1958); for Pro, the forma- tion of stable complexes is supported by the cyclic nature of this AA (Nelson and Cox, 2013). Moreover, the stability of iron-Pro complexes is superior in terms of proteolysis, because Pro-rich peptides show enhanced resistance to digestion enzymes (Yaron et al., 1993). We previously reported an increase in iron stability and solubility by the action of these hydrolysates shown by an iron dialyzability enhancement (de la Hoz et al., 2014a).

In conclusion, we identified peptide sequences with iron-binding capacity from whey proteins for the first time. Peptides were obtained by hydrolysis of whey

$\frac{\text { us }}{4}$

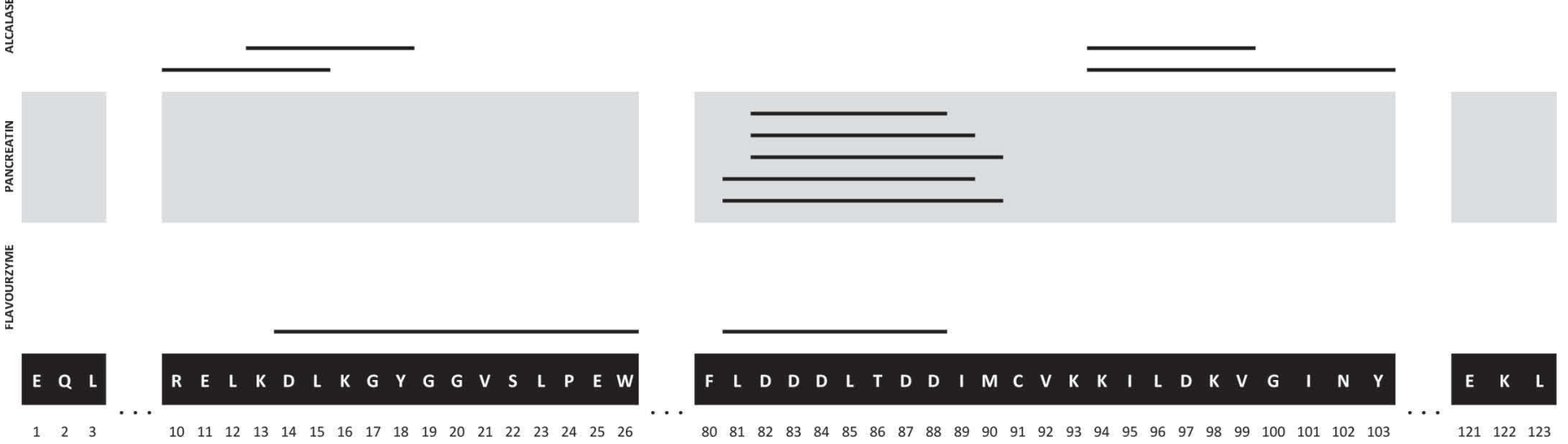

Figure 3. Schematic representation of peptides identified from bovine $\alpha$-LA in fractions derived from iron (III)-immobilized metal ion affinity chromatography for different enzymatic treatments: Alcalase (Novozymes, Araucaria, PR, Brazil), pancreatin, and Flavourzyme (Novozymes). Identification was performed by reversed-phase HPLC-tandem mass spectrometry. 
WPH IMAC-Fe (III)
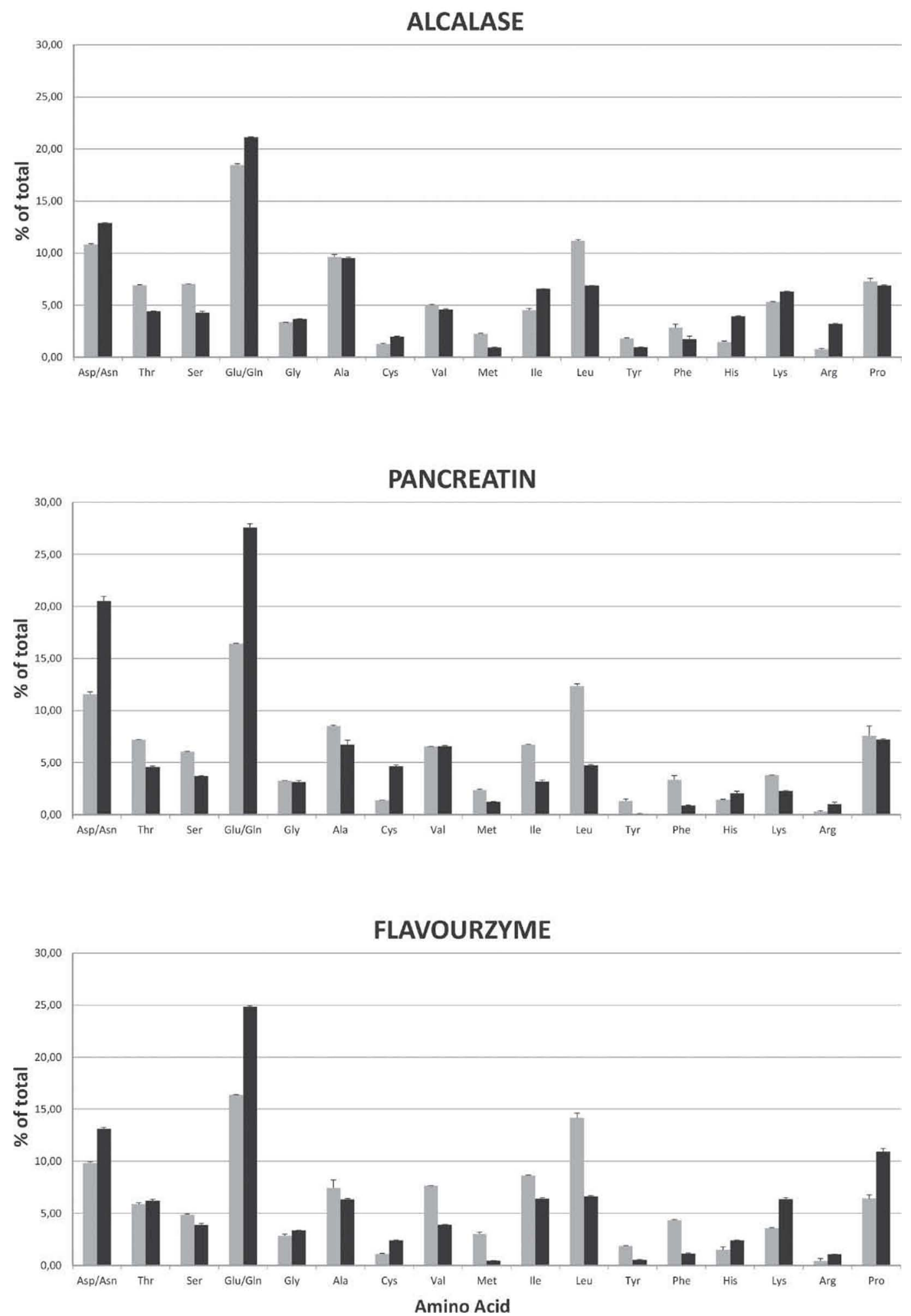

Figure 4. Amino acid content determined by Biochrom 30 Amino Acid Analyzer (Amersham-Pharmacia Biotech, Piscataway, NJ). Data were expressed, for each AA, as mean and standard deviation of the percentage (\%) of the sum of all AA identified (n = 2); Asn and Gln were detected as Asp and Glu, respectively, due to their deamination during the preparation step; Trp completely degraded during the analysis. WPH $=$ fraction $<5 \mathrm{kDa}$; IMAC-Fe (III) = the iron (III)-immobilized metal ion affinity chromatography fraction. 
protein isolate using 3 different enzymes: Alcalase, pancreatin, and Flavourzyme. Regardless of which enzyme was used to prepare the hydrolysates, the domains $\mathrm{f}(42-59)$ and $\mathrm{f}(125-137)$ from $\beta-\mathrm{LG}$ enclosed most of identified peptides in the chromatographic bound fraction. Iron-bound peptide pools from IMAC-Fe (III) also exhibited common characteristics, such as the abundance of the iron-chelating AA Asp, Glu, and Pro. Nevertheless, each enzyme presented particular properties in terms of the specific proportion of certain AA and had different specificities for major whey proteins. This characterization of iron-binding peptides helps clarify the relationship between peptide structure and iron-chelating activity and supports the role of whey protein hydrolysates as functional ingredients in iron supplementation treatments. Additional studies of iron uptake should be carried out by simulating gastric digestion in cellular and in vivo models to assess their capacity.

\section{ACKNOWLEDGMENTS}

This work received financial support from projects AGL2011-24643 from the Ministerio de Economía y Competitividad of Spain; CONETA-PEME IN852A 2013/39-0 from Xunta de Galicia of Spain; FP7SME-2012-315349 (FOFIND) from the European Union; Fundaçao de Amparo a Pesquisa de Sao Paulo, Brazil; and IBEROFUN 110AC0386 from Programa Iberoamericano de Ciencia y Tecnología para el Desarrollo. E. C.-H. thanks the Universidad Veracruzana and the Program for the Improvement of Teaching (PROMEP) of México for awarding the scholarship for supporting $\mathrm{PhD}$ studies abroad.

\section{REFERENCES}

de la Hoz, L., V. S. Nunes da Silva, M. A. Morgano, and M. T. B. Pacheco. 2014a. Small peptides from enzymatic whey hydrolysates increase dialyzable iron. Int. Dairy J. 38:145-147. de la Hoz, L., A. N. Ponezi, R. F. Milani, V. S. Nunes da Silva, A Sonia de Souza, and M. T. Bertoldo-Pacheco. 2014b. Iron-binding properties of sugar cane yeast peptides. Food Chem. 142:166-169.

Guo, L., P. A. Harnedy, B. Li, H. Hou, Z. Zhang, X. Zhao, and R. J. FitzGerald. 2014. Food protein-derived chelating peptides: Biofunctional ingredients for dietary mineral bioavailability enhancement. Trends Food Sci. Technol. 37:92-105.

Kim, S. B., I. S. Seo, M. A. Khan, K. S. Ki, M. S. Nam, and H. S. Kim. 2007. Separation of iron-binding protein from whey through enzymatic hydrolysis. Int. Dairy J. 17:625-631.

Martínez-Maqueda, D., B. Miralles, M. Ramos, and I. Recio. 2013. Effect of $\beta$-lactoglobulin hydrolysate and $\beta$-lactorphin on intestinal mucin secretion and gene expression in human goblet cells. Food Res. Int. 54:1287-1291.

Nelson, D. L., and M. M. Cox. 2013. Chapter 5. Pages 157-189 in Lehninger Principles of Biochemistry. W.H. Freeman Publishers, New York, NY.

O'Keeffe, M. B., and R. J. FitzGerald. 2014. Antioxidant effects of enzymatic hydrolysates of whey protein concentrate on cultured human endothelial cells. Int. Dairy J. 36:128-135.

O'Loughlin, I. B., B. A. Murray, R. J. FitzGerald, A. Brodkorb, and P. M. Kelly. 2014. Pilot-scale production of hydrolysates with altered bio-functionalities based on thermally-denatured whey protein isolate. Int. Dairy J. 34:146-152.

Otte, J., M. Zakora, K. B. Qvist, C. E. Olsen, and V. Barkholt. 1997. Hydrolysis of bovine $\beta$-lactoglobulin by various proteases and identification of selected peptides. Int. Dairy J. 7:835-848.

Ou, K., Y. Liu, L. Zhang, X. Yang, Z. Huang, M. J. R. Nout, and J. Liang. 2010. Effect of neutrase, alcalase, and papain hydrolysis of whey protein concentrates on iron uptake by Caco-2 cells. J. Agric. Food Chem. 58:4894-4900.

Perrin, D. D. 1958. The stability of complexes of ferric ion and amino acids. J. Chem. Soc. 3125-3128.

Smithers, G. W. 2008. Whey and whey proteins-From 'gutter-togold'. Int. Dairy J. 18:695-704.

Storcksdieck genannt Bonsmann, S., and R. F. Hurrell. 2007. Ironbinding properties, amino acid composition, and structure of muscle tissue peptides from in vitro digestion of different meat sources. J. Food Sci. 72:S019-S029.

Sugiarto, M., A. Ye, and H. Singh. 2009. Characterisation of binding of iron to sodium caseinate and whey protein isolate. Food Chem. 114:1007-1013.

WHO/FAO. 2004. Vitamin and Mineral Requirements in Human Nutrition. 2nd ed. World Health Organization, Geneva, Switzerland.

Yaron, A., F. Naider, and S. Scharpe. 1993. Proline-dependent structural and biological properties of peptides and proteins. Crit. Rev. Biochem. Mol. Biol. 28:31-81.

Zhou, J., X. Wang, T. Ai, X. Cheng, H. Y. Guo, G. X. Teng, and X. Y. Mao. 2012. Preparation and characterization of $\beta$-lactoglobulin hydrolysate-iron complexes. J. Dairy Sci. 95:4230-4236. 